\title{
A Standardized Chinese Herbal Decoction, Kai-Xin-San, Restores Decreased Levels of Neurotransmitters and Neurotrophic Factors in the Brain of Chronic Stress-Induced Depressive Rats
}

\author{
Kevin Yue Zhu, ${ }^{1}$ Qing-Qiu Mao, ${ }^{2}$ Siu-Po Ip, ${ }^{2}$ Roy Chi-Yan Choi, ${ }^{1}$ Tina Ting-Xia Dong, \\ David Tai-Wai Lau, ${ }^{1}$ and Karl Wah-Keung Tsim ${ }^{1}$ \\ ${ }^{1}$ Division of Life Science, Center for Chinese Medicine and State Key Laboratory of Molecular Neuroscience, \\ The Hong Kong University of Science and Technology, Clear Water Bay Road, Hong Kong \\ ${ }^{2}$ School of Chinese Medicine, The Chinese University of Hong Kong, Shatin, N.T., Hong Kong \\ Correspondence should be addressed to Karl Wah-Keung Tsim, botsim@ust.hk
}

Received 20 April 2012; Revised 16 June 2012; Accepted 10 July 2012

Academic Editor: Kelvin Chan

Copyright ( $) 2012$ Kevin Yue Zhu et al. This is an open access article distributed under the Creative Commons Attribution License, which permits unrestricted use, distribution, and reproduction in any medium, provided the original work is properly cited.

Kai-xin-san (KXS), a Chinese herbal decoction being prescribed by Sun Simiao in Beiji Qianjin Yaofang about 1400 years ago, contains Ginseng Radix et Rhizoma, Polygalae Radix, Acori tatarinowii Rhizoma, and Poria. KXS has been used to treat stressrelated psychiatric disease with the symptoms of depression and forgetfulness in ancient China until today. However, the mechanism of its antidepression action is still unknown. Here, the chronic mild-stress-(CMS-) induced depressive rats were applied in exploring the action mechanisms of KXS treatment. Daily intragastric administration of KXS for four weeks significantly alleviated the CMS-induced depressive symptoms displayed by enhanced sucrose consumption. In addition, the expressions of those molecular bio-markers relating to depression in rat brains were altered by the treatment of KXS. These KXS-regulated brain biomarkers included: (i) the levels of dopamine, norepinephrine, and serotonin (ii) the transcript levels of proteins relating to neurotransmitter metabolism; (iii) the transcript levels of neurotrophic factors and their receptors. The results suggested that the anti-depressant-like action of KXS might be mediated by an increase of neurotransmitters and expression of neurotrophic factors and its corresponding receptors in the brain. Thus, KXS could serve as alternative medicine, or health food supplement, for patients suffering from depression.

\section{Introduction}

Today, a lot of people are suffering from a depressive episode. If a person encounters these symptoms, for example, anhedonia (loss of interest and pleasure), persistent depression, difficulty in sleeping, suicidal tendency, occuring together and lasting for more than two weeks without significant improvement, thus major depression disorder is being diagnosed [1]. The major depression disorder (depression) today is a common psychiatric disorder having an incidence up to $15 \%$ and perhaps higher for women at $25 \%$ [2], which is estimated to be a major burden on mental health service by the year of 2020 according to WHO's prediction.

Currently, several therapies are used for the treatment of depression, which can be categorized into two parts, psychotherapy and pharmacotherapy, supplemented with other therapies, for example, electroconvulsive seizures, deep brain stimulation, and exercises [3]. The modulation of neurotransmitters, especially restoring the decreased level in the brain of depressive patients, had become the target for development of anti-depression drugs. At least three categories of antidepression drugs have been developed: (i) the tricyclic anti-depressants, such as imipramine, dothiepin, and clomipramine, (ii) the selective neurotransmitters reuptake inhibitors, such as selective serotonin reuptake inhibitors, and norepinephrine reuptake inhibitors, norepinephrinedopamine reuptake inhibitors, and (iii) monoamine oxidase inhibitors. However, about $30 \%-40 \%$ of patients are not responding to an initial 4-6-week treatment with these drugs. About $10-15 \%$ of patients fail to improve sufficiently, 
even after several attempts of different treatments, while $12-$ $15 \%$ of depressive patients show no response at all, not to mention the possible side effects [4]. Therefore, other theories of the etiology of depression have been proposed, and the deficiency of neurotrophic factors in the brain is an important one [5].

Traditional Chinese medicine (TCM) has offered a possible therapy for the treatment of depression. The records of treating mental disorders could be found in ancient medicinal books, and a herbal decoction kai-xin-san (KXS) is the most popular one. The first description of KXS is recorded in Beiji Qianjin Yaofang < Thousand Formulae for Emergency> written by Sun Simiao in Tang Dynasty (i.e., 652 AD). This herbal formula composes of four herbs: Ginseng Radix et Rhizoma (root and rhizome of Panax ginseng C. A. Mey.), Polygalae Radix (root of Polygala tenuifolia Wild.), Acori Tatarinowii Rhizoma (rhizome of Acorus tatarinowii Schott), and Poria (sclerotium of Poria cocos (Schw.) Wolf). KXS has been used to treat the diseases having symptoms of depressed mood and morbid forgetfulness [6]. Although this decoction has been used frequently, the mechanism of KXS for anti-depression is still unknown, which therefore hinders the further clinical application of this herbal formula. Here, we applied chronic mild-stress-(CMS-) induced depressive rat models to search the mechanism of KXS on anti-depression. The long-term treatment of a chemical standardized herbal extract of KXS suppressed the CMSinduced depression in rats. In the brains of KXS-treated rats, the levels of neurotransmitters, the mRNA expressions of crucial enzymes in regulating those neurotransmitters, and the mRNA expressions of neurotrophic factors and its receptors were significantly altered.

\section{Materials and Methods}

2.1. Chemicals. Dopamine hydrochloride, 5-hydroxyindoleacetic acid, serotonin hydrochloride, and norepinepherine were purchased from Sigma-Aldrich (St. Louis, MO, USA). Internal standards with isotope labeling were 2-(3,4dihydroxyphenyl)ethyl-1,1,2,2- $\mathrm{d}_{4}$-amine $\mathrm{HCl}$ (dopamine$\mathrm{d}_{4}, 98$ atom \% D); 5-hydroxyindole-4,6,7- $\mathrm{d}_{3}-3$-acetic- $\mathrm{d}_{2}$ acid (5-hydroxyindole-3-acetic acid- $\mathrm{d}_{5}, 98$ atom \% D); Lglutamic-2,3,3,4,4- $\mathrm{d}_{5}$-acid (glutamate- $\mathrm{d}_{5}, 98$ atom \% D); serotonin- $\alpha, \alpha, \beta, \beta-\mathrm{d}_{4}$ creatinine sulfate complex (serotonin$\mathrm{d}_{4}, 98$ atom \% D); norepinepherine-2,5,6, $\alpha, \beta, \beta-\mathrm{d}_{6} \mathrm{HCl}$ (norepinepherine- $\mathrm{d}_{6}, 98$ atom $\left.\% \mathrm{D}\right)$. The internal standards were purchased from CDN Isotopes (Quebec, Canada). LC-MSgrade acetonitrile and water were purchased from Capitol Scientific (Austin, TX, USA). Formic acid was purchased from Riedel-de Haën Inc. (Hannover, Germany). Imipramine was purchased from Sigma-Aldrich. RNAzol reagent was purchased from Molecular Research Center (Cincinnati, $\mathrm{OH}$, USA). High-Capacity cDNA Reverse Transcription Kit was purchased from Applied Biosystems (Foster City, CA, USA). KAPA SYBR FAST qPCR Kit was purchased from Kapa Biosystems (Woburn, MA, USA).

2.2. Preparation of Extract of KXS Decoction. KXS decoction composed of the following dried raw materials: $4 \mathrm{~g}$ Ginseng
Radix et Rhizome (root and rhizome of $P$. ginseng), 4 g Polygalae Radix (root of $P$. tenuifolia), $100 \mathrm{~g}$ Acori Tatarinowii Rhizoma (rhizome of A. tatarinowii), and $200 \mathrm{~g}$ Poria (sclerotium of $P$. cocos). The herbs were purchased from Qingping Market of Chinese herbs in Guangzhou, China, which were authenticated by one of the authors, Dr. Tina T.X. Dong, according to their morphological characteristics. The voucher specimens were deposited in the Centre for Chinese Medicine at Hong Kong University of Science and Technology. The herb materials were combined and boiled in $2,500 \mathrm{~mL}$ of water for 2 hours, and the herbs were extracted twice. For the second extraction of KXS, the residue from the first extraction was filtered: the same extraction condition was applied on the filtered residue. Then, the extracts were combined and concentrated to the powder and stored at $-80^{\circ} \mathrm{C}$. Before the KXS treatment, the powder was re-dissolved and vortexed in room temperature. The herbal extract was chemically standardized as reported previously [7].

2.3. Animals and Drug Treatment. Male Sprague-Dawley rats weighing 200-220 g were obtained from the Laboratory Animal Services Center, Chinese University of Hong Kong. Animals were maintained on a 12-hour light/dark cycle (lights on at 6:00 a.m., lights off at 6:00 p.m.) under controlled temperature $\left(22 \pm 2^{\circ} \mathrm{C}\right)$ and humidity $(50 \pm 10 \%)$, and they were given standard diet and water. They were allowed to acclimatize for 7 days before use. The experiments on animals have been approved by the Animal Experimentation Ethics Committee of the Chinese University of Hong Kong and conformed to the guidelines of "Principles of Laboratory Animal Care" (NIH publication no. 80-23, revised 1996). The efforts were made to minimize the number and suffering of animals. Rats were randomly divided into five groups of eight individuals. The control animals were given with saline. For another four groups, the animals were treated simultaneously with chronic mild stress (CMS). The drugs (KXS at 0.9 and $2.7 \mathrm{~g} / \mathrm{kg} /$ day and imipramine at $20 \mathrm{mg} / \mathrm{kg}$ ) were intragastrically given daily at $30 \mathrm{~min}$ before the stress exposure for the entire 4-week treatment.

2.4. Chronic Mild Stress Procedure. The procedure of CMS was performed as described previously [8]. In brief, the CMS protocol consisted of the sequential application of a variety of mild stressors: (1) food deprivation for 24 hours, (2) water deprivation for 24 hours, (3) exposure to a empty bottle for 1 hours, (4) cage tilt $\left(45^{\circ}\right)$ for 7 hours, (5) overnight illumination, (6) soiled cage $(200 \mathrm{~mL}$ water in $100 \mathrm{~g}$ sawdust bedding) for 24 hours, (7) forced swimming at $8^{\circ} \mathrm{C}$ for 6 minutes, (8) physically restraint for 2 hours, and (9) exposure to a foreign object (e.g., a piece of plastic) for 24 hours. These stressors were randomly scheduled over a one-week period and repeated throughout the 4 weeks of experiment (see Figure 1). Nonstressed animals were left undisturbed in their home cages except during housekeeping procedures such as cage cleaning.

2.5. Rat Sucrose Preference Test. Sucrose preference test was carried out at the end of 4-week CMS exposure. The test was performed as described previously with minor 


$\begin{array}{ccccccc}\text { Day } 1 & \text { Day } 2 & \text { Day } 3 & \text { Day } 4 & \text { Day } 5 & \text { Day 6 } & \text { Day 7 } \\ \begin{array}{c}\text { Food } \\ \text { deprivation }\end{array} & \begin{array}{c}\text { Empty } \\ \text { bottle }\end{array} & \begin{array}{c}\text { Forced } \\ \text { swimming }\end{array} & \text { Restraint } & \begin{array}{c}\text { Food } \\ \text { deprivation }\end{array} & \begin{array}{c}\text { Water } \\ \text { deprivation }\end{array} & \begin{array}{c}\text { Empty } \\ \text { bottle }\end{array} \\ \begin{array}{c}\text { Water } \\ \text { deprivation }\end{array} & \begin{array}{c}\text { Foreign } \\ \text { object }\end{array} & \begin{array}{c}\text { Overnight } \\ \text { illumination }\end{array} & \begin{array}{c}\text { Tilted } \\ \text { cage }\end{array} & \begin{array}{c}\text { Soiled } \\ \text { cage }\end{array} & \begin{array}{c}\text { Overnight } \\ \text { illumination }\end{array} & \begin{array}{c}\text { Tilted } \\ \text { cage }\end{array}\end{array}$

Figure 1: Schedule of chronic mild stress (CMS) procedure. The CMS protocol consisted of the sequential application of a variety of mild stressors. These stressors were randomly scheduled over a one-week period from Day 1 to Day 7 and repeated for 4 weeks during the entire experiment.

modifications. Briefly, 72 hours before the test, the rats were trained to adapt to $1 \%$ sucrose solution $(\mathrm{w} / \mathrm{v})$ : two bottles of $1 \%$ sucrose solution were placed in each cage, and 24 hours later $1 \%$ sucrose in one bottle was replaced with tap water for 24 hours. After the adaptation, rats were deprived of water and food for 24 hours. Sucrose preference test was conducted at 9:00 a.m. in which rats were housed in individual cages and were free to access to two bottles containing $100 \mathrm{~mL}$ of sucrose solution $(1 \%, \mathrm{w} / \mathrm{v})$ and $100 \mathrm{~mL}$ of water, respectively. After 3 hours, the volumes of consumed sucrose solution and water were measured, and the sucrose preference was calculated by the following formula: sucrose preference $=$ sucrose consumption $/($ water consumption + sucrose consumption) $\times 100 \%[8]$.

2.6. Analysis of Neurotransmitters. The rats were sacrificed by decapitation, and the whole brain tissues were dissected. Brain tissues were rapidly frozen in liquid nitrogen and kept in $-80^{\circ} \mathrm{C}$ for storage. For lysate preparation, the brain tissues were homogenized in ice-cold $0.5 \mathrm{M}$ formic acid with the concentration of $5 \mathrm{~mL} / \mathrm{g}$ tissue, in the presence of the internal standard at $500 \mathrm{ng} / \mathrm{g}$ tissue. The lysates were centrifuged $15,000 \times \mathrm{g}$ for $30 \mathrm{~min}$ at $4^{\circ} \mathrm{C}$. The supernatant was separated and stored at $-20^{\circ} \mathrm{C}$ until the LC-MS analysis. The detection of neurotransmitters analysis was performed as described [9]. The chromatographic separation was performed on an Agilent UHPLC 1290 series system (Agilent, Waldbronn, Germany), which was equipped with a degasser, a binary pump, an autosampler, and a thermostated column compartment. The brain sample was separated on an ACE C18 column $(3.0 \mu \mathrm{m}$ i.d., $100 \mathrm{~mm} \times 2.1 \mathrm{~mm})$. The mobile phase was composed of $0.1 \%$ formic acid in water (A) and $0.1 \%$ formic acid in acetonitrile (B) using the following gradient program: $0-2 \mathrm{~min}$, isocratic gradient $1.0 \%(\mathrm{~B}) ; 2-6 \mathrm{~min}$, linear gradient $1.0-90.0 \%$ (B); 6-10 min, isocratic gradient $90.0 \%$ (B). A preequilibration period of $4 \mathrm{~min}$ was used between each run. The flow rate was $0.2 \mathrm{~mL} / \mathrm{min}$, the column temperature was $25^{\circ} \mathrm{C}$, and the injection volume was $5 \mu \mathrm{L}$. An Agilent QQQ-MS/MS (6410A) equipped with an ESI ion source was operated in positive ion mode. The following conditions were optimized: drying gas, nitrogen (10 $\mathrm{L} / \mathrm{min}, 325^{\circ} \mathrm{C}$ ); capillary voltage, $1950 \mathrm{~V}$; scan mode, SRM. The detected ion pairs, the acquired fragmentor, and the collision energy were tuned with the aids of Agilent optimization software (B02.01). The mass spectrometry calibration was performed with the autofeature of Agilent Mass Hunter Chemstation software (version B01.03) using the ESI-L low-concentration tuning mix supplied with the apparatus. Agilent Mass Hunter workstation software version B.01.00 was used for data acquisition and processing.

2.7. Total RNA Extraction. Total RNA from brain tissue was isolated with RNAzol reagent according to the manufacturer's protocol. In details, total brain tissues were added with RNAzol reagent $(1.5 \mathrm{~mL} / \mathrm{g})$ and homogenized. The homogenate was centrifuged at $16,100 \times \mathrm{g}$ for $5 \mathrm{~min}$ at $4^{\circ} \mathrm{C}$. The supernatants were removed, added with diethylpyrocarbonate-(DEPC-) treated water (prepared by autoclaving water with DEPC in a 1000:1 ratio), and vortexed vigorously for $15 \mathrm{sec}$, followed by centrifugation at 13,500 rpm $(16,100$ $\times \mathrm{g}$ ) for $10 \mathrm{~min}$ at $4^{\circ} \mathrm{C}$. The aqueous layer was collected and added with half volume of $70 \%$ ethanol in DEPC-treated water for RNA precipitation. The RNA pallet was collected by centrifugation at $16,100 \times \mathrm{g}$ for $10 \mathrm{~min}$ at $4^{\circ} \mathrm{C}$ and washed with 70\% ethanol in DEPC-treated water twice. After air dry, the RNA was re-suspended in $200 \mu \mathrm{L}$ of DEPC-treated water. Concentrations of extracted RNA were calculated from the UV absorbance at $260 \mathrm{~nm}$. The quality of RNA was assessed by absorbance at $260 \mathrm{~nm}$ and $280 \mathrm{~nm}$, with the ratio of 260 / $280 \mathrm{~nm}$ ranging from 1.90 to 2.10 being acceptable.

2.8. Real-Time Quantitative PCR. Isolated RNAs were reverse transcribed by the moloney murine leukemia virus (MMLV) reverse transcriptase with oligo- $\mathrm{d}(\mathrm{T})$ primer in a $20 \mu \mathrm{L}$ reaction by using High-Capacity cDNA Reverse Transcription Kit. In details, three $\mu \mathrm{g}$ of total RNA was mixed with $1 \mu \mathrm{L}$ of $0.5 \mu \mathrm{g} / \mathrm{mL}$ oligo-d(T) primer, $1 \mu \mathrm{L}$ of $10 \mathrm{mM} \mathrm{dNTP}$ mix, and RNAase/DNAase-free water in a $12 \mu \mathrm{L}$ reaction. The mixture was incubated in $65^{\circ} \mathrm{C}$ for $5 \mathrm{~min}$. Two $\mu \mathrm{L}$ of $0.1 \mathrm{M}$ dithiothreitol (DTT), $1 \mu \mathrm{L}$ of $40 \mathrm{U} / \mu \mathrm{L}$ RNase out, and $4 \mu \mathrm{L}$ of $5 \times$ first strand buffer $(250 \mathrm{mM}$ Tris- $\mathrm{HCl}, \mathrm{pH}$ $8.3,375 \mathrm{mM} \mathrm{KCl}, 15 \mathrm{mM} \mathrm{MgCl}_{2}$ ) were added into the reaction mix and incubated at $37^{\circ} \mathrm{C}$ for $5 \mathrm{~min}$. One $\mu \mathrm{L} \mathrm{MMLV}$ was added into the reaction and incubated at $37^{\circ} \mathrm{C}$ for $50 \mathrm{~min}$. Then, the reaction was incubated at $70^{\circ} \mathrm{C}$ for 15 min. Quantification of the cDNA was determined by UV absorbance at $260 \mathrm{~nm}$ and $280 \mathrm{~nm}$ by NanoDrop. Applications were performed in an Applied Biosystems PCR system for 40 cycles. Ten $\mu \mathrm{L}$ aliquots of the PCR products were size-separated by electrophoresis on a $2 \%$ agarose gel. Real-time quantitative PCR was performed by using SYBR Green Master mix and ROX reference dye, according to the manufacturer's instructions of KAPA SYBR FAST qPCR Kit. In brief, cDNAs were obtained from the reverse 


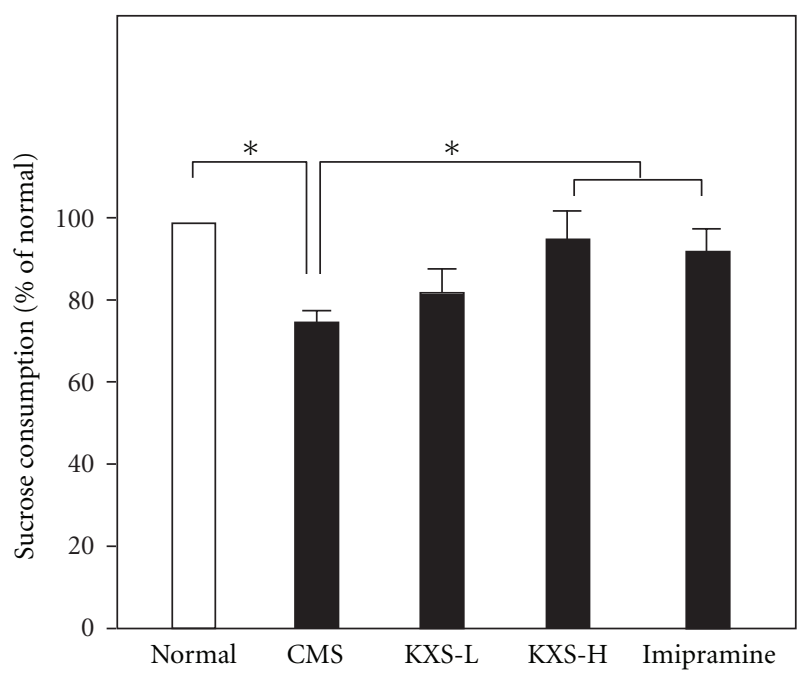

(a)

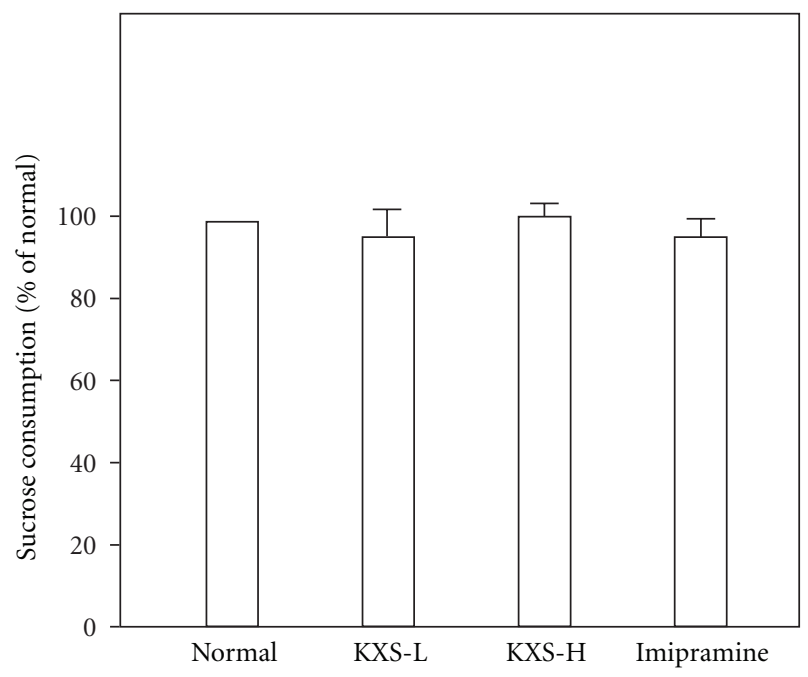

(b)

FIGURE 2: KXS increases the sucrose consumption in CMS-treated rats. (a) Five groups of rats were employed for the sucrose preference test, as stated in Figure 1. KXS treatment, intra-gastrically, was administrated daily at $30 \mathrm{~min}$ before the stress exposure for 4 weeks of experimental period. Two doses of KXS were applied including low dosage at $0.9 \mathrm{~g} / \mathrm{kg}$ (KXS-L) and high dosage at $2.7 \mathrm{~g} / \mathrm{kg}$ (KXS$\mathrm{H})$. Imipramine at daily dosage of $20 \mathrm{mg} / \mathrm{kg}$ was set as a positive control. (b) Treatment of KXS and imipramine as in (a) but these were all in normal rats. Values are expressed in the percentage of normal (unstressed, or no drug, control), as mean $\pm \operatorname{SEM}(n=8)$. $* P<0.05$.

transcription of the RNA from rat brain. SYBR green signal was detected by $\mathrm{M} \times 3000$ ptm multiplex quantitative PCR machine. Transcript levels were quantified by using the $\mathrm{Ct}$ value method [11], where values were normalized by the internal-control GAPDH in the same sample. PCR products were analyzed by gel electrophoresis on a $1.5 \%$ agarose gel, and the specificity of amplification was confirmed by the melting curves. Primers employed in RT-PCR and real-time quantitative PCR analyses were listed in Table 1.

\section{Results}

3.1. KXS Alleviates the Depressive-Like Symptoms Induced by Chronic Mild Stress. A chemically standardized herbal extract was prepared according to the ancient recipe: this was an important prerequisite criterion to ensure the repeatability of KXS treatment. KXS was prepared by having Ginseng Radix et Rhizoma, Polygalae Radix, Acori Tatarinowii Rhizoma, and Poria in a ratio of $1: 1: 25: 50$. A standardized extraction method of herbal extraction and a quantification of KXS chemically by HPLC-DAD-MS/MS method were developed previously [7]. In addition, an HPLC-MS/MS fingerprint of KXS was shown in Supplementary Figure avalible online at doi:10.1155/2012/149256: this was to ensure the quality of the herbal decoction. By determining the amounts of marker chemicals from each herb, we recommended that a standardized KXS extract should contain no less than $20.4 \pm$ $1.7 \mathrm{mg}$ of ginsenoside $\mathrm{Rb}_{1}, 8.0 \pm 0.6 \mathrm{mg}$ of ginsenoside $\mathrm{Rd}$, $19.0 \pm 1.3 \mathrm{mg}$ of ginsenoside Re, $24.6 \pm 2.2 \mathrm{mg}$ of ginsenoside $\mathrm{Rg}_{1}, 33.6 \pm 0.3 \mathrm{mg}$ of $3,6^{\prime}$-disinapoyl sucrose, $51.4 \pm 0.2 \mathrm{mg}$ of $\alpha$-asarone, $1112.4 \pm 1.9 \mathrm{mg}$ of $\beta$-asarone, $21.1 \mathrm{e}^{-3} \pm 0.4 \mathrm{e}^{-3} \mathrm{mg}$ of pachymic acid, in $100 \mathrm{~g}$ of KXS extract, and the yield of KXS was $14.3 \pm 6 \%$ (mean $\pm \mathrm{SD}, n=3$ ). These parameters established the chemical standards of KXS for subsequent studies on animals.

To evaluate the anti-depression efficacy of KXS on animal model, the depressive rats induced by CMS were employed for this exploration. The CMS paradigm involved the exposure of animals to a series of mild and unpredictable stressors for 4 weeks (Figure 1). The effect of KXS treatment on the percentage of sucrose consumption in CMS-treated rats was shown in Figure 2(a). Five groups of rats were employed for the sucrose preference test. Imipramine at daily dosage of $20 \mathrm{mg} / \mathrm{kg}$ was set as a positive control. KXS treatment was set for two dosages: low dosage (KXS-L) at $0.9 \mathrm{~g} / \mathrm{kg}$ and high dosage (KXS-H) at $2.7 \mathrm{~g} / \mathrm{kg}$. The applied KXS dosage here was estimated according to the current clinical usage in human. A 4-week CMS exposure significantly reduced the percentage of sucrose consumption by $\sim 21 \%$ in the animals as compared to the nonstressed control. The long-term treatment of KXS-H increased the sucrose consumption in CMS-treated rats $(\sim 20 \%)$, as compared to the CMS-treated control, that is, an improved behavior. The treatment of imipramine increased the percentage of sucrose consumption in CMS-treated rats $(\sim 18 \%)$. The long-term treatment with KXS-L also showed an increase in tendency $(\sim 15 \%)$, but without statistical significance. Both treatments almost restored the sucrose consumption back to the normal condition. The treatment of KXS, or imipramine, in normal rats however did not show any significant effect on the sucrose consumption (Figure 2(b)). Thus, KXS exerted a profound anti-depression effect in alleviating the depressive-like symptom on CMS-induced depressive rats.

3.2. KXS Restores the Decreased Level of Neurotransmitters in Brain of the Depressive Rats. The developed HPLC-MS/MS method was employed to determine the total levels of neurotransmitters in the brain of CMS-treated rats [9]. The effects of KXS and imipramine on the amount of 
TABLE 1: Primer sequences, length of PCR products and optimal annealing temperature for each gene used in real-time quantitative PCR.

\begin{tabular}{|c|c|c|c|c|}
\hline Primer & Sequence $\left(5^{\prime}-3^{\prime}\right)$ & Source & bp & $\mathrm{Ta}\left({ }^{\circ} \mathrm{C}\right)$ \\
\hline TH-S & CCA GTT CTC CCA GGA CAT TGG AC & \multirow{2}{*}{ NM_012740.3 } & \multirow{2}{*}{312} & \multirow{2}{*}{59} \\
\hline TH-AS & GAG GCA TAG TTC CTG AGC TTG TCC & & & \\
\hline DBH-S & GAA GAA TGC TGT GAC TGT CCA CCA G & \multirow{2}{*}{ NM_013158.2 } & \multirow{2}{*}{387} & \multirow{2}{*}{59} \\
\hline DBH-AS & CAG AGG CTG CAG GTT CCA GTT AC & & & \\
\hline AADC-S & GTT GTC ACC CTA GGA ACC ACA TCT TG & \multirow{2}{*}{ NM_012545.3 } & \multirow{2}{*}{444} & \multirow{2}{*}{59} \\
\hline AADC-AS & CTC ATG AGA CAG CTT CAC GTG CTT TC & & & \\
\hline $\mathrm{MAO}_{\mathrm{A}}-\mathrm{S}$ & GCC AAA GTT CTG GGA TCT CAA GAA GC & \multirow{2}{*}{ NM_033653.1 } & \multirow{2}{*}{204} & \multirow{2}{*}{59} \\
\hline $\mathrm{MAO}_{\mathrm{A}}$-AS & CAC CAG TGA TCT TGA GCA GAC CAG & & & \\
\hline $\mathrm{MAO}_{\mathrm{B}}-\mathrm{S}$ & GAG AAG AAC TGG TGT GAG GAG CAG & \multirow{2}{*}{ NM_013198.1 } & \multirow{2}{*}{342} & \multirow{2}{*}{59} \\
\hline $\mathrm{MAO}_{\mathrm{B}}$-AS & AGC TGT TGC TGA CAA GAT GGT GGT & & & \\
\hline COMT-S & GGT GAC GCG AAA GGC CAA ATC ATG & \multirow{2}{*}{ NM_012531.2 } & \multirow{2}{*}{351} & \multirow{2}{*}{59} \\
\hline COMT-AS & CAG GCC ACA TTT CTC CAG GAG AAG & & & \\
\hline DAT-S & GGT TCT ACG GCG TCC AGC AAT TC & \multirow{2}{*}{ M80570.1 } & \multirow{2}{*}{291} & \multirow{2}{*}{59} \\
\hline DAT-AS & CAT AGG CCA GTT TCT CCC GGA AG & & & \\
\hline VMAT2-S & GGT GGA CTC CTC TAT GAT GCC TAT C & \multirow{2}{*}{ NM_013031.3 } & 351 & 59 \\
\hline VMAT2-AS & CTC CTT AGC AGG TGG ACT TCG AAG & & 年 & קוב \\
\hline NET-S & CAG GTT CAG CAA TGA CAT CCA GCA G & NM 0313431 & 282 & 59 \\
\hline NET-AS & GTG ATT CCG TAG GCC ACT CTC TC & NIM_031343.1 & 282 & 39 \\
\hline DrD2-S & AAC TGT ACC CAC CCT GAG GAC ATG & NM 012547.1 & 236 & 59 \\
\hline DrD2-AS & CTG TCA GGG TTG CTA TGT AGG CC & NM_01254/.1 & 200 & 59 \\
\hline AdralA-S & TGG TGG GTT GCT TCG TCC TCT G & NM 0171912 & 211 & 59 \\
\hline Adra1A-AS & CGA AGA CAC TGG ATT CGC AGG AC & NM_01/191.2 & 211 & \\
\hline TPH-S & CAC CCA GGA TTC AAG GAC AAC GTC & NM 1738392 & 421 & 59 \\
\hline TPH-AS & CAC TGT GAA GCC AGA TCG CTC TTT C & & & \\
\hline SERT-S & ATG GTT CGT GCT CAT CGT GGT CAT C & NM 0130343 & 268 & 59 \\
\hline SERT-AS & GAT GAA CAG GAG AAA CAG AGG GCT G & NIMI_U15054.J & 200 & 39 \\
\hline Htr1A-S & CAT CAG CAA GGA CCA CGG CTA C & NM 0125851 & 353 & 59 \\
\hline Htr1A-AS & GGA AGG TGC TCT TTG GAG TTG CC & NM__012583.1 & 353 & 39 \\
\hline NGF-S & CAC TCT GAG GTG CAT AGC GTA ATG TC & XP 0010671302 & 374 & 59 \\
\hline NGF-AS & CTG TGA GTC CTG TTG AAG GAG ATT GTA C & XP_00106/130.2 & $3 / 4$ & 59 \\
\hline BDNF-S & GAG CTG AGC GTG TGT GAC AGT ATT AG & BC087634 & 220 & 59 \\
\hline BDNF-AS & ATT GGG TAGT TCG GCA TTG CGA GTT C & BCU8/634 & 229 & 59 \\
\hline GDNF-S & GCG CTG ACC AGT GAC TCC AAT ATG & AF497634 & 318 & 59 \\
\hline GDNF-AS & CGC TTC ACA GGA ACC GCT ACA ATAT C & AF 497634 & 318 & 59 \\
\hline NT3-S & ACA AGC TCT CCA AGC AGA TGG TAG ATG & M61179.1 & 310 & 59 \\
\hline NT3-AS & TCT CCT CGG TGA CTC TTA TGC TCT G & MO11/9.1 & 310 & 39 \\
\hline NT4-S & TCA GTA CTT CTT CGA GAC GCG CTG & NM 0131843 & 135 & 59 \\
\hline NT4-AS & GGC ACA TAG GAC TGT TTA GCC TTG CAT & & & \\
\hline NT5-S & ATG CAG TGA GTG GCT GGG TGA C & $\$ 693231$ & 229 & 59 \\
\hline NT5-AS & GTT TAG CCT TGC ATT CTG AGA GCC AG & 569323.1 & & \\
\hline TrkA-S & ACC TCA ACC GTT TCC TCC GGT C & M85214 & 330 & 57 \\
\hline TrkA-AS & CTC GAT CGC CTC AGT GTT GGA GA & & 350 & Jו \\
\hline TrkB-S & CGG GAG CAT CTC TCG GTC TAT G & M552911 & 221 & 57 \\
\hline TrkB-AS & CAA ATG TGT CCG GCT TGA GCT GG & M135291.1 & 221 & \\
\hline TrkC-S & CAC TGT CTA CTA CCC TCC ACG TG & L03813. & 253 & 57 \\
\hline TrkC-AS & CTC TCT GGA AAG GGC TCC TTA AGG & L03813.1 & 253 & $5 /$ \\
\hline GAPDH-S & AAC GGA TTT GGC CGT ATT GG & Lee et al., $2009[10]$ & 516 & 57 \\
\hline GAPDH-AS & CTT CCC GTT CAG CTC TGG G & & & \\
\hline
\end{tabular}

Abbreviations: S: sense primer; AS: antisense primer; TH: tyrosine hydroxylase; $\mathrm{DBH}$ : dopamine $\beta$-hydroxylase; AADC: aromatic acid decarboxylase; $\mathrm{MAO}_{\mathrm{A}}$ : monoamine oxidase $\mathrm{A} ; \mathrm{MAO}_{\mathrm{B}}$ : monoamine oxidase B; COMT: catechol-O-methyltransferase; DAT: dopamine transporter; VMAT2: vesicular monoamine transporter 2; NET: norepinepherine transporter; DrD2: dopamine receptor D2; Adra1A: adrenergic receptor $\alpha 1 \mathrm{~A}$; Htr 1A: serotonin receptor 1A; TPH: tryptophan hydroxylase; SERT: serotonin transporter; Htrla: serotonin receptor 1A; NGF: nerve growth factor; BDNF: brain derived neurotrophic factor; GDNF: glial-cell-line-derived neurotrophic factor; NT3: neurotrophin 3; NT4: neurotrophin 4; NT5: neurotrophin 5; Trk A: tyrosine kinase receptor A; Trk B: tyrosine kinase receptor B; Trk C: tyrosine kinase receptor C; GAPDH: glyceraldehyde-3-phosphate dehydrogenase. 

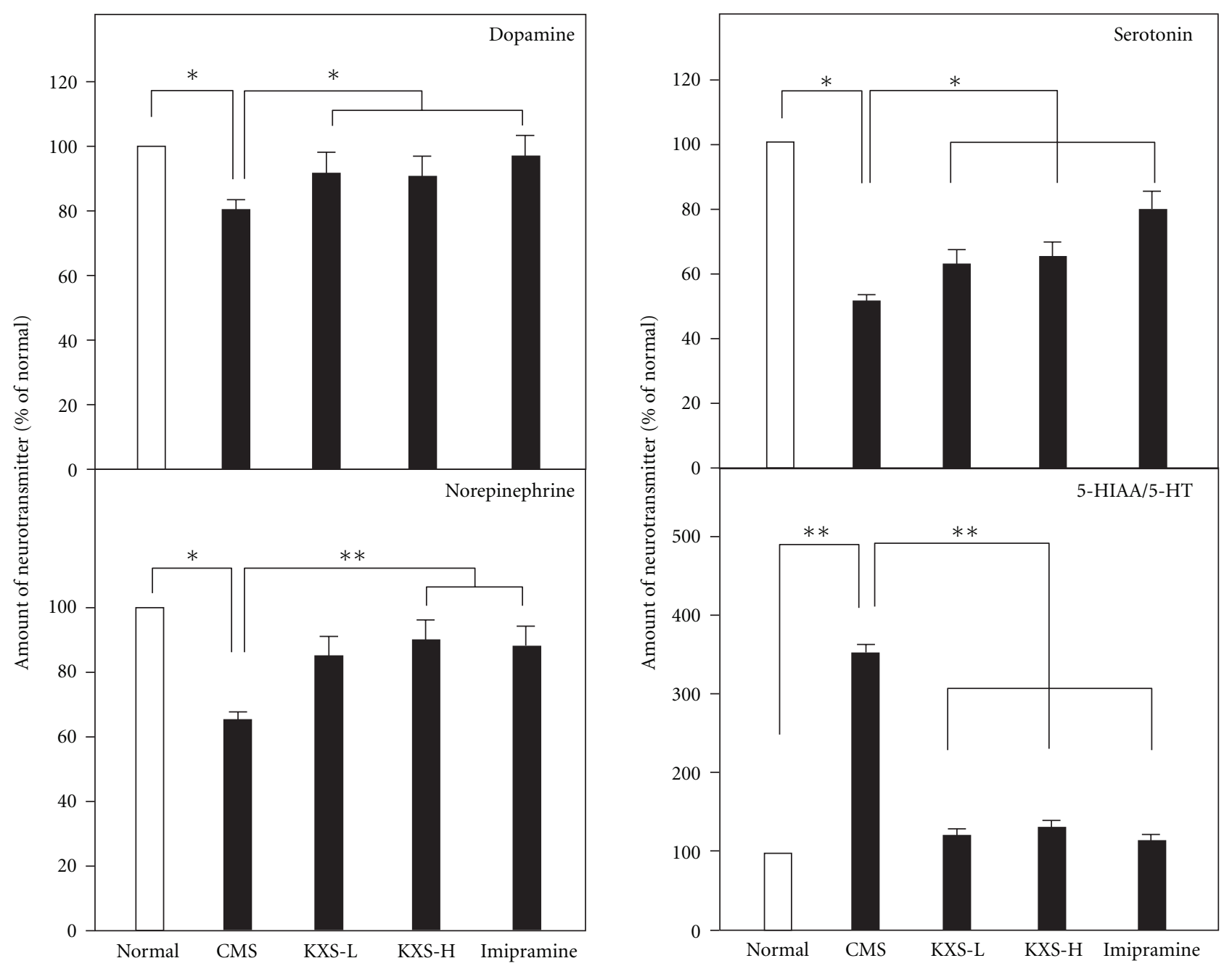

FIGURE 3: KXS restores the decreased level of neurotransmitters in depressive rats. The treatment of KXS in the rats was as that in Figure 2. The total brain was collected after the treatment. The amounts of dopamine, norepinepherine, serotonin, and 5-HIAA in rat brains were analyzed by LC-MS. Two doses of KXS were applied including low dosage at $0.9 \mathrm{~g} / \mathrm{kg}$ (KXS-L) and high dosage at $2.7 \mathrm{~g} / \mathrm{kg}(\mathrm{KXS}-\mathrm{H})$. The imipramine at dose of $20 \mathrm{mg} / \mathrm{kg}$ was set as the positive control. Values are showed as the mean $\pm \operatorname{SEM}(n=8)$. ${ }^{*} P<0.05 * * P<0.01$.

neurotransmitters in the brains were summarized in Figure 3. In the CMS-treated rat brains, the reductions of norepinepherine, dopamine, and serotonin were significantly revealed: the decrease was from 20 to 50\%. Imipramine treatment was able to fully reverse the effects of CMS on the amounts of norepinepherine, dopamine, and serotonin in the brain. The treatment with KXS, both low and high doses, was effective in reversing the effect of CMS on norepinepherine and dopamine; that is, the levels returned to normal control (Figure 3 ).

Here, the amounts of serotonin and 5-hydroxyindoleacetic acid (5-HIAA), a metabolite of serotonin, were analyzed in the KXS-treated rat brains. The ratio of 5-HIAA to serotonin could be used as an index for the turnover of serotonin $[12,13]$. The amount of serotonin was markedly reduced in the CMS-treated rat brains (Figure 3). In parallel, the amount of 5-HIAA was markedly increased, that is, an increase of serotonin breakdown. This CMS-induced phenomenon could be significantly reversed by the treatment of KXS, as well as the control treatment of imipramine
(Figure 3). The reduced 5-HIAA/5-HT ratio suggested that the turnover of serotonin was decreased by the treatment of KXS.

\subsection{KXS Regulates the mRNA Expression of Proteins Relating} to the Regulation of Neurotransmitters. The mRNA levels of proteins relating to the regulation of dopamine and norepinephrine (see Table 1) were determined by quantitative PCR: these proteins included tyrosine hydroxylase, dopamine $\beta$-hydroxylase, monoamine oxidase $\mathrm{B}$, catechol- $\mathrm{O}$ methyltransferase, dopamine transporter, norepinepherine transporter, dopamine receptor 2 , and norepinepherine receptor. The mRNAs encoding enzymes accounting for the metabolism of dopamine and norepinepherine were significantly altered, except tyrosine hydroxylase and monoamine oxidase B, in the CMS-treated rat brains (Figure 4). As compared to CMS control, the KXS treatment could significantly increase the mRNA levels of tyrosine hydroxylase at $\sim 3$-fold under KXS-H, dopamine $\beta$-hydroxylase at $\sim 2$-fold under both KXS-L and KXS-H, and monoamine oxidase B from 

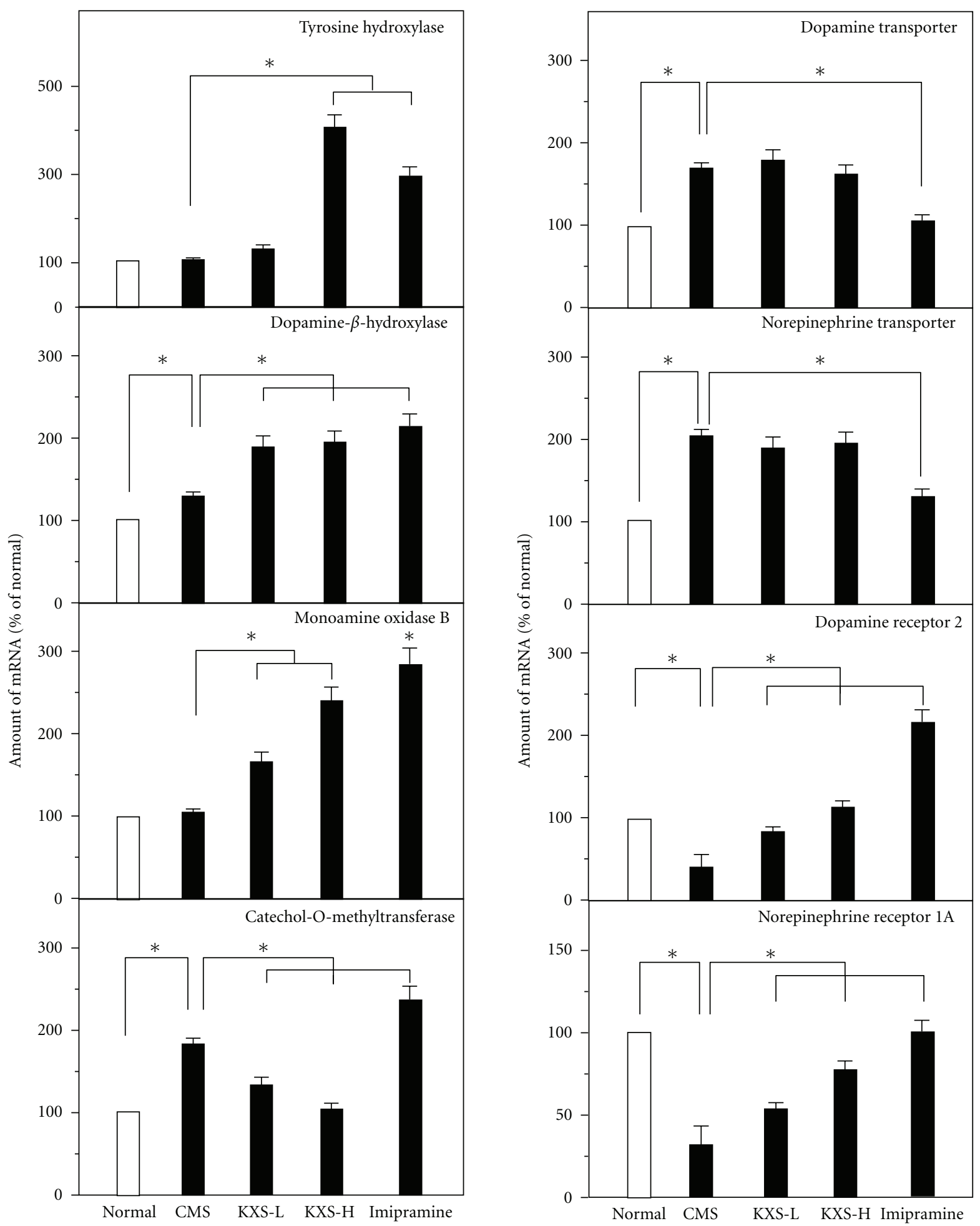

FIGURE 4: KXS regulates the mRNA expression of proteins relating to catecholamine metabolism in depressive rats. The treatment of KXS in the rats was as that in Figure 2. The total RNA was isolated from the rat brains. The mRNA expression was analyzed by real-time quantitative PCR. Two doses of KXS were applied including low dosage at $0.9 \mathrm{~g} / \mathrm{kg}$ (KXS-L) and high dosage at $2.7 \mathrm{~g} / \mathrm{kg}$ (KXS-H). The imipramine at dose of $20 \mathrm{mg} / \mathrm{kg}$ was set as the positive control. Values are showed as the mean $\pm \operatorname{SEM}(n=8) .{ }^{*} P<0.05$. 
1.8-fold to 2.5-fold under KXS-L and KXS-H, respectively (Figure 4). In contrast, the level of mRNA encoding catecholO-methyltransferase was markedly reduced in the KXStreated depressive rats. Increase of synthesizing enzymes and decrease of degrading enzymes could account for the restoration of dopamine and norepinepherine back to the normal concentration. For the transporters of dopamine and norepinepherine, the mRNA levels of dopamine transporter and norepinepherine transporter were significantly increased in the CMS-treated rat brains (Figure 4). This tendency could be reversed by the imipramine treatment, while the KXS treatment had no effect. For dopamine receptor D2 and norepinepherine receptor $1 \mathrm{~A}$ (adrenergic receptor $\alpha 1 \mathrm{~A}$ ), CMS could significantly downregulate the mRNA level of the receptors in rat brains (Figure 4). Here, both KXS and imipramine treatments could restore the decreased levels back to the normal condition.

The mRNA levels of regulating proteins relating to serotonin metabolism (see Table 1) were also determined. The mRNAs encoding tryptophan hydroxylase, aromatic acid decarboxylase and monoamine oxidase A were determined. These mRNAs were significantly reduced under the CMS treatment (Figure 5). The KXS treatment in both dosages restored the mRNA levels of tryptophan hydroxylase, aromatic acid decarboxylase, and monoamine oxidase A. Imipramine could only restored the levels of mRNAs encoding aromatic acid decarboxylase, and monoamine oxidase A (Figure 5). The mRNA expressions of transporter and receptor for serotonin were also determined under the herbal treatment. The CMS-suppressed mRNA levels of these proteins were restore by the treatment of KXS significantly, except serotonin receptor $1 \mathrm{~A}$ (Figure 5).

3.4. Effect of KXS on mRNA Expression Levels of Proteins Related to the Regulation of Neurotrophic Factors. The deficiency of neurotrophic factors in the brain was one of the theories in accounting for depression. Here, the expression levels of mRNA encoding NGF, BDNF, GDNF, NT3, NT4, and NT5 and their related receptors were explored. In the CMStreated rat brains, the mRNA expressions of neurotropic factors were significantly reduced in all cases (Figure 6). The treatment of KXS in CMS-treated rats could increase the expressions of NGF, BDNF, GDNF, NT3, and NT5 mRNAs but not the mRNA of NT4. In contrast, the treatment of imipramine did not show any effect on the CMS-reduced mRNA expression of those neurotropic factors, except GDNF (Figure 6). In addition, the mRNA expressions of Trk A, Trk $\mathrm{B}$, and Trk $\mathrm{C}$ receptors were determined: these expressions showed a reduction in the CMS-treated rat brains (Figure 7). In parallel, the levels of $\operatorname{Trk} A, \operatorname{Trk} B$ and Trk $C$ receptors in the CMS-treated rat brains were restored under the treatment of KXS. Imipramine treatment could only restore the CMS-suppressed Trk A and Trk B receptors (Figure 7).

\section{Discussions}

KXS, an ancient Chinese herbal decoction, has been used in Chinese medicinal herbal mixture in treating anti-depression; however, the action mechanism of which in brain functions has not been revealed. Here, we provided different lines of evidence to support the anti-depression role of KXS in CMS rat model system. The intake of KXS in the CMS-treated rats could result in the following: (i) the sucrose consumption was increased; (ii) the amounts of dopamine, norepinephrine, and serotonin, as well as its metabolic proteins including the transporters and receptors, were regulated; (iii) the amounts of NGF, BDNF, GDNF, NT3, NT4, and NT5, as well as their receptors including Trk A and Trk B, were increased. Under this scenario, the regulation of neurotransmitters and neurotropic factors could lead to a result of the improved behavior of those CMS-treated rats. However, the molecular targets of KXS in the brains have not been revealed, in particular this herbal mixture is containing numerical amount of chemicals [7].

The four individual herbs of KXS are known to affect our nervous system and frequently applied in the treatment, or the prevention, of anti-depression, no matter in a form of single herb or in an herbal mixed formula [14]. In KXS, the four herbs could be separated into two herb pairs. The pair of Ginseng Radix et Rhizoma and Polygalae Radix is to invigorate the Xin-qi, while that of Acori Tatarinowii Rhizoma and Poria is to eliminate the dampness. The pharmacological effects of active chemicals deriving from these four herbs on anti-depression have been reported. The total saponins derived from Ginseng Radix et Rhizoma, especially ginsenosides, are the main chemicals with strong neurotrophic and neuroprotective effects [15]. Indeed, the saponins of Ginseng Radix et Rhizoma were shown to reverse the reduction in sucrose preference index in CMS-treated rats through enhancing the amount of monoamine neurotransmitter [16] and the expression of BDNF mRNA in hippocampus and frontal cortex of the brain [17]. In CMStreated rats, the oligosaccharide ester of Polygalae Radix increased sucrose consumption, reduced the levels of cortistatin, adrenocorticotropic hormone, and corticotropin-releasing factor in serum, and also enhanced the expression of glucocorticoid receptor mRNA $[18,19]$. The water extract of Acori Tatarinowii Rhizoma could significantly shortened the motionless time of forced swimming and the despair time of tail suspension in mouse animal models of depression [20]. Compared to other herbs, the studies of neuronal function of Poria are very limited, in spite of its widely application in treating mental disorder by herbalists. In line to its clinical usages, the water extract of Poria protected cultured PC12 cells through suppressing the oxidative stress and the apoptosis induced by $\mathrm{A} \beta$ [21]. The triterpenoids from Poria could regulate the expressed 5-HT3A receptors in Xenopus oocytes [10]. Although each herb showed the potent effect in anti-depression, a herbal mixed formula of four herbs was frequently applied clinically instead of a single form, according to the usages of Chinese medicine.

The first catecholamine theory of depression was proposed in 1965 [22]. Thus, the aim of the drug development was to restore the decreased levels of neurotransmitters in the synaptic cleft or in the depressive brain. Dopamine, norepinepherine, and serotonin were regarded as the crucial neurotransmitters in the etiology of depression. Indeed, many 

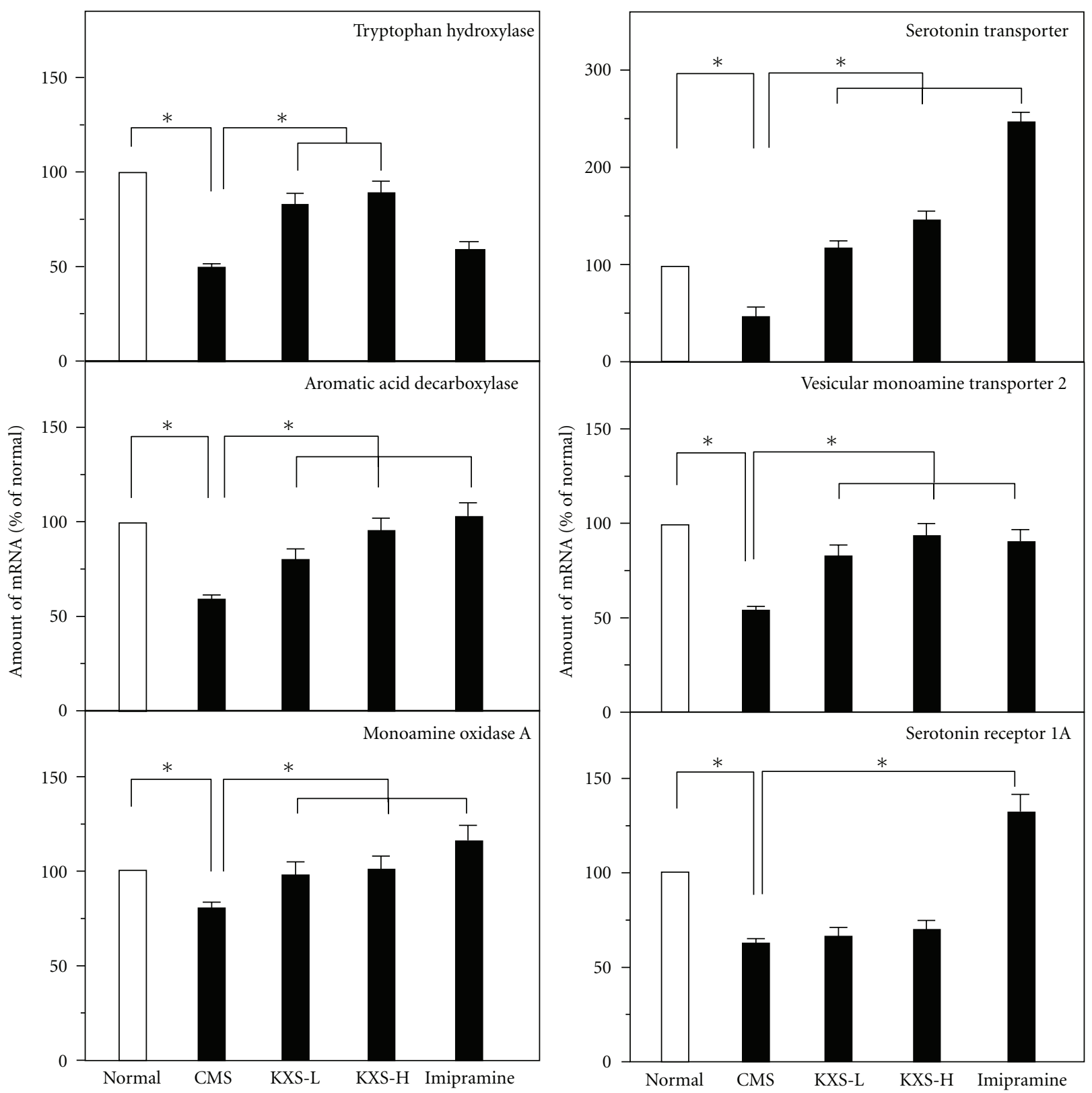

FIGURE 5: KXS regulates the mRNA expression of proteins relating to serotonin in depressive rats. The treatment of KXS in the rats was as that in Figure 2. The total RNA was isolated from the rat brains. The mRNA expression was analyzed by real-time quantitative PCR. Two doses of KXS were applied including low dosage at $0.9 \mathrm{~g} / \mathrm{kg}$ (KXS-L) and high dosage at $2.7 \mathrm{~g} / \mathrm{kg}$ (KXS-H). The imipramine at dose of $20 \mathrm{mg} / \mathrm{kg}$ was set as the positive control. Values are showed as the mean $\pm \operatorname{SEM}(n=8)$. ${ }^{*} P<0.05$.

drugs targeting to the neurotransmitter metabolism have been developed, for example, reserpine, tetrabenazine, iproniazid, and imipramine [4]. In the present studies, KXS treatment tended to restore the levels of dopamine, norepinepherine and serotonin in the CMS-treated rat brains: the restored levels were similar to that in the nonstressed group. Compared to the positive control imipramine, one of the first-generation tricyclic anti-depression drug and norepinepherine and serotonin reuptake inhibitors, KXS showed similar effects, which implied that it might exert anti-depression actions by modulating dopaminergic, noradrenalinergic, and serotoninergic neuronal systems.
In order to explore the mechanism of neurotransmitter regulation, the mRNA expression levels of related proteins were evaluated. For dopamine and norepinepherine, they share the same biosynthesis pathway at the start point, while that of serotonin has a distinct pathway (Figure 8). In the treatment of KXS in those CMS-treated rats, the enzymes responding for synthesis of dopamine/norepinephrine, and serotonin were increased, for example, tyrosine hydroxylase, dopamine $\beta$-hydroxylase, and aromatic acid decarboxylase. Under the CMS treatment, the brain receptors for dopamine and norepinepherine, and the transporter of serotonin were increased. Based on the results, KXS might regulate the 

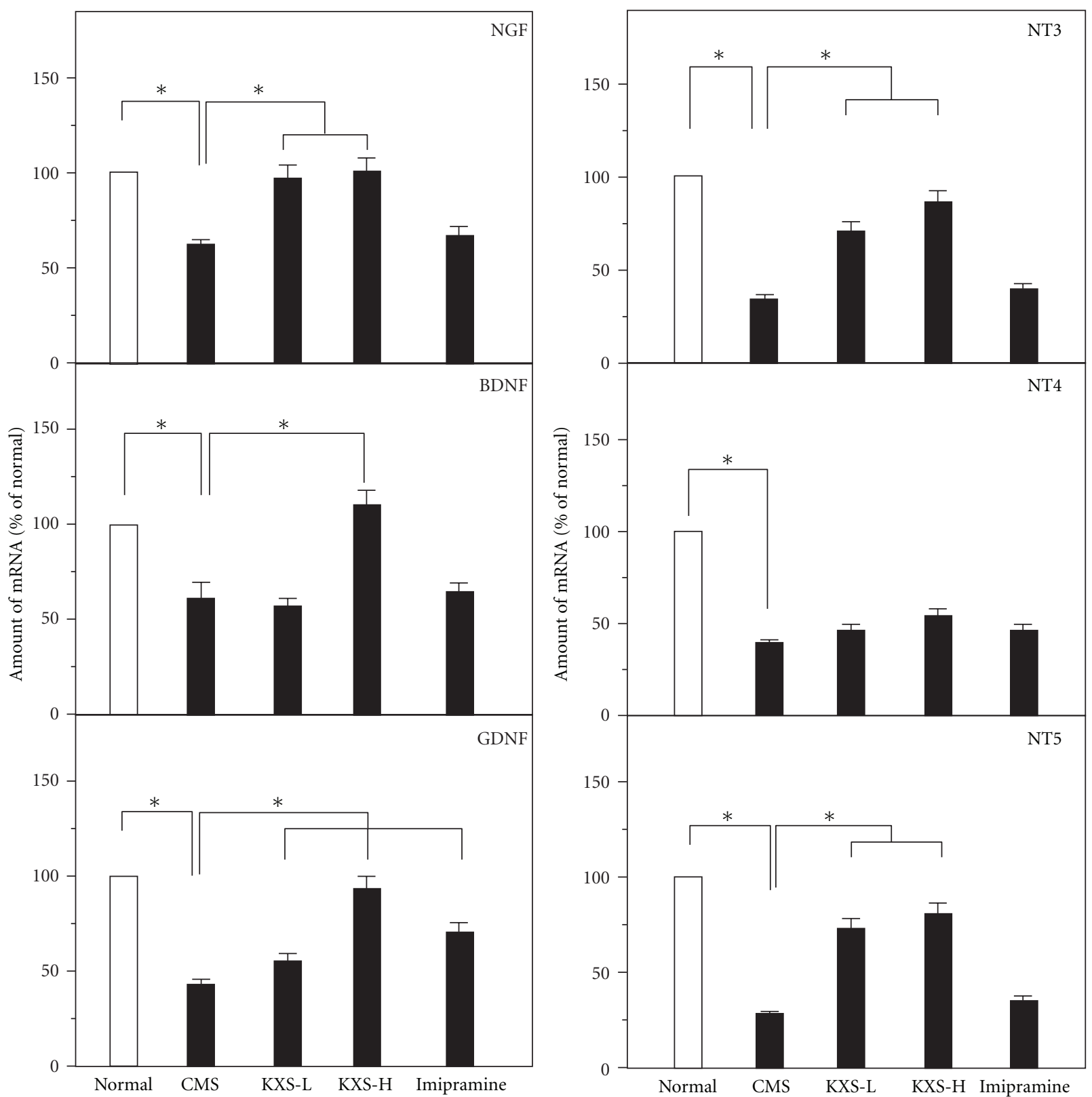

FIGURE 6: KXS increases the mRNA expression of neurotrophic factors in depressive rats. The treatment of KXS in the rats was as that in Figure 2. The total RNA was isolated from the rat brains. The mRNA expression was analyzed by real-time quantitative PCR. Two doses of KXS were applied including low dosage at $0.9 \mathrm{~g} / \mathrm{kg}$ (KXS-L) and high dosage at $2.7 \mathrm{~g} / \mathrm{kg}(\mathrm{KXS}-\mathrm{H})$. The imipramine at dose of $20 \mathrm{mg} / \mathrm{kg}$ was set as the positive control. Values are showed as the mean $\pm \operatorname{SEM}(n=8) .{ }^{*} P<0.05$.

neurotransmitter systems by acting on synthesis, storage, and upregulating the receptors in order to compensate for the deficient availability of neurotransmitters caused by the depressive state. Although imipramine could upregulate the levels of neurotransmitters, the regulations on those aforementioned proteins are very different to that of KXS treatment.

The theory of neurotrophic factors in the etiology of depression has attracted much attention. The theory holds that the normal physiology of neuron is supported and maintained with the help of a series of neurotrophic factors, including NGF, BDNF, GDNF, NT-3, NT-4, and
NT-5. If the deficiency of neurotrophic factors occurred, the neuron cannot survive and/or grow healthy, which will subsequently lead to neurodegenerative disorders, for example, depression. Postmortem analyses of brain tissues from patients with major depression showed a reduction in brain BDNF [23] and in serum BDNF [24, 25], whereas brain infusion of BDNF produced anti-depressant-like action in animals [26]. In addition, NGF was also found to have novel anti-depressant-like action in rats, but did not appear to have biochemical actions similar to that of other anti-depressants [27]. In the present study, the CMS-treated rat showed a decrease in the expression of neurotrophic factors and its 


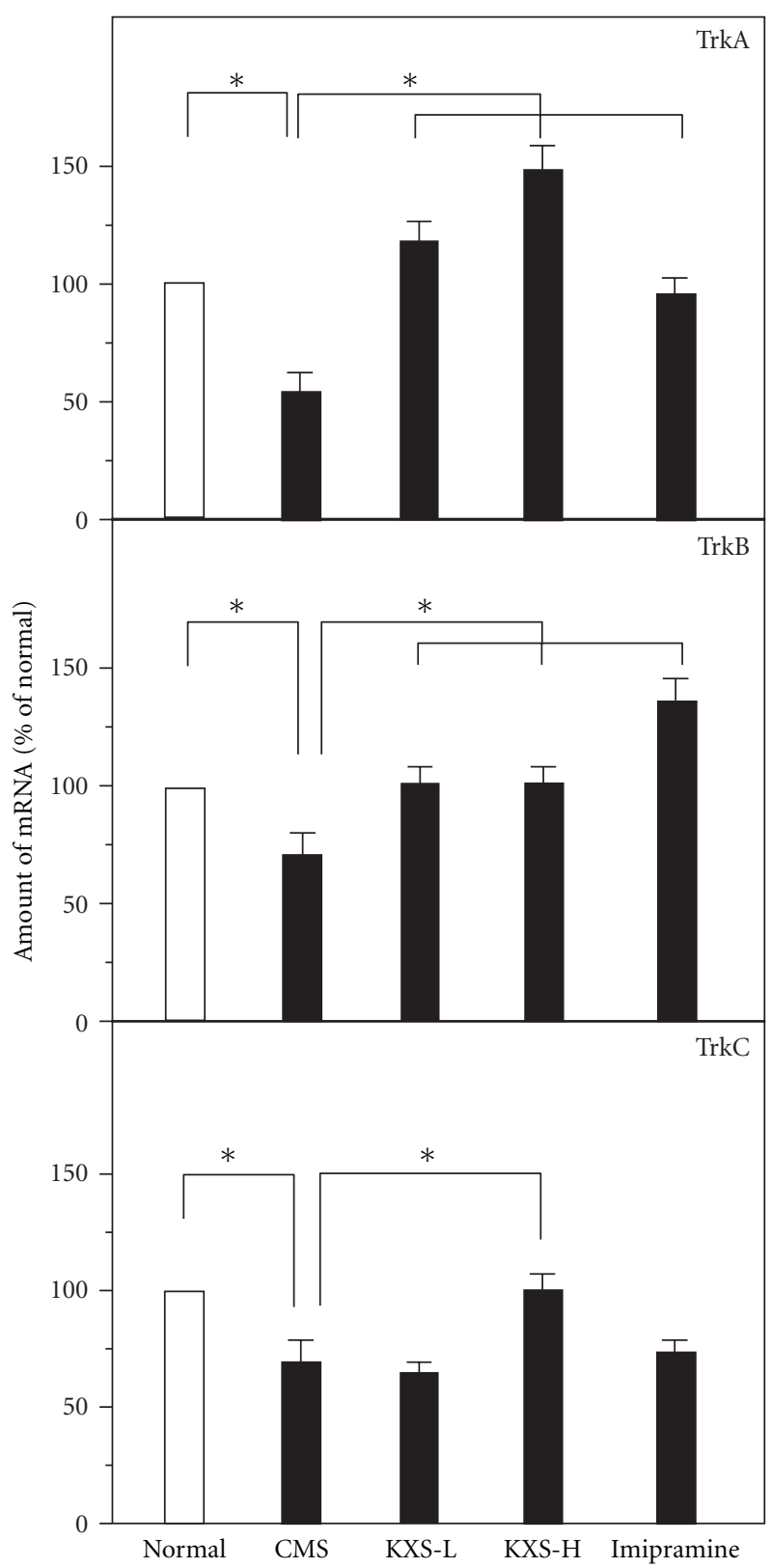

FIgURE 7: KXS increases the mRNA expression of neurotrophic receptors in depressive rats. The treatment of KXS in the rats was as that in Figure 2. The total RNA was isolated from the rat brains. The mRNA expression was analyzed by real-time quantitative PCR. Two doses of KXS were applied including low dosage at $0.9 \mathrm{~g} / \mathrm{kg}$ (KXS$\mathrm{L}$ ) and high dosage at $2.7 \mathrm{~g} / \mathrm{kg}(\mathrm{KXS}-\mathrm{H})$. The imipramine at dose of $20 \mathrm{mg} / \mathrm{kg}$ was set as the positive control. Values are showed as the mean $\pm \operatorname{SEM}(n=8) .{ }^{*} P<0.05$.

corresponding receptors. However, KXS could increase the expression levels of neurotrophic factors and its receptors in restoring abnormal growth state of neuron under depression. Indeed, our preliminary results suggested that the application of KXS onto cultured astrocytes could induce the expression of neurotrophic factors (Zhu et al., unpublished results). For imipramine in CMS-treated rats, only the

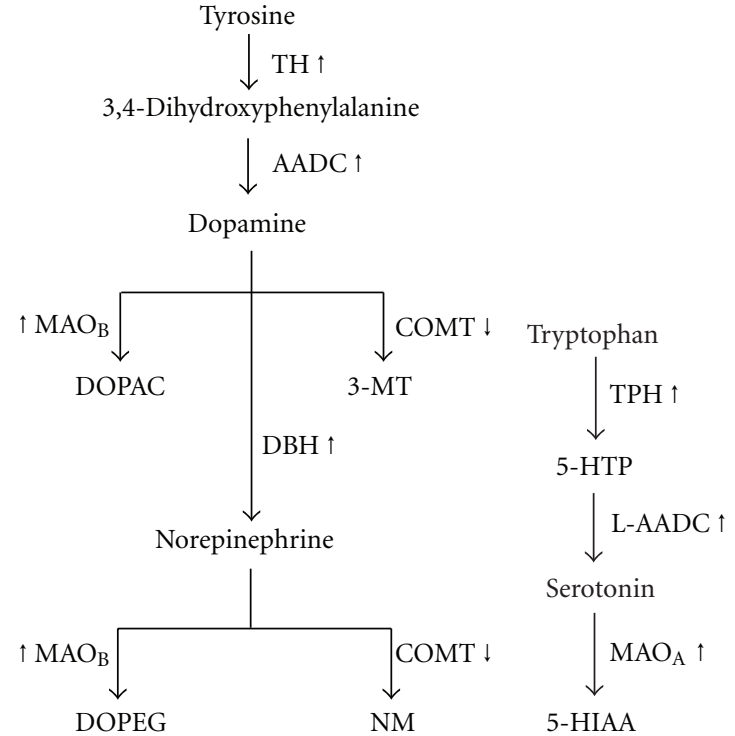

(a)

(b)

FIGURE 8: Synthesis and degradation of dopamine, norepinephrine, and serotonin. The detailed pathway of the synthesis and degradation of dopamine, norepinepherine (a) and serotonin (b) were shown. The arrows indicate the up- and downregulation of the corresponding mRNA level by the treatment of KXS. TH: tyrosine hydroxylase; AADC: aromatic acid decarboxylase; $\mathrm{MAO}_{\mathrm{B}}$ : monoamine oxidase B; COMT: catechol-O-methyl-transferase; DOPAC: dihydroxyphenylacetic acid; 3-MT: 3-methoxytyramine; DBH: dopamine $\beta$-hydroxylase; DOPEG: dihydroxyphenylglycol; NM: normetanephrine; TPH: tryptophan hydroxylase; 5-HTP: 5hydroxytryptophan; $\mathrm{MAO}_{\mathrm{A}}$ : monoamine oxidase A; 5-HIAA: 5hydroxyindole-3-acetic acid.

expression of GDNF level was elevated, which was also consistent with a previous report [28].

Based on our current study, KXS might have multitargets in the brain for anti-depression. These findings are in line with previous studies. KXS treatment in rats has been shown to enhance the learning and memory abilities [29]. In parallel, KXS, in different ratio of the four herbs, was found to exert profound effects in anti-depression [16]. Thus, KXS could be a valuable herbal formula for the treatment of antidepression, either as a form of health food supplement or a prescribed drug. More importantly, the toxicity of long-term intake of KXS has been very minimal, which has made it be used over a thousand of years in human [30].

\section{Conclusions}

The treatment of KXS could alleviate the depression-like symptoms in CMS-induced rats. The anti-depressive action of KXS might be accounted by modulating the neurotransmitters system and increasing the expression of neurotrophic factors in the brain. This herbal extract is being chemically standardized and therefore could serve as alternative medicine or health food supplement for patients suffering from depression. Since KXS is a mixture of compounds, 
the identification of active ingredients here will be further evaluated.

\section{Acknowledgments}

This research was supported by grants from the University Grants Committee (AoE/B-15/01), the Research Grants Council of Hong Kong (HKUST 6419/06 M, 662608, 662911, N_HKUST629/07), and The Croucher Foundation (CASCF07/08.SC03) awarded to K. Tsim.

\section{References}

[1] G. Parker, "Beyond major depression," Psychological Medicine, vol. 35, no. 4, pp. 467-474, 2005.

[2] C. Lanni, S. Govoni, A. Lucchelli, and C. Boselli, "Depression and antidepressants: molecular and cellular aspects," Cellular and Molecular Life Sciences, vol. 66, no. 18, pp. 2985-3008, 2009.

[3] M. D. Binder, N. Hirokawa, and U. Windhorst, Encyclopedia of Neuroscience, Springer, Berlin, Germany, 2009.

[4] S. M. Stahl, Stahl's Essential Psychopharmacology: Neuroscientific Basis and Practical Applications, Cambridge University Press, Cambridge, UK.

[5] V. Krishnan and E. J. Nestler, "The molecular neurobiology of depression," Nature, vol. 455, no. 7215, pp. 894-902, 2008.

[6] S. M. Sun, Beiji QIanjin Yaofang JIaoshi, People Medicinal Publishing House, Beijing, China, 1998.

[7] K. Y. Zhu, Q. Fu, H. Q. Xie et al., "Quality assessment of a formulated Chinese herbal decoction, Kaixinsan, by using rapid resolution liquid chromatography coupled with mass spectrometry: a chemical evaluation of different historical formulae," Journal of Separation Science, vol. 33, no. 23-24, pp. 3666-3674, 2010.

[8] Q. Q. Mao, S. P. Ip, K. M. Ko, S. H. Tsai, and C. T. Che, "Peony glycosides produce antidepressant-like action in mice exposed to chronic unpredictable mild stress: effects on hypothalamicpituitary-adrenal function and brain-derived neurotrophic factor," Progress in Neuro-Psychopharmacology and Biological Psychiatry, vol. 33, no. 7, pp. 1211-1216, 2009.

[9] K. Y. Zhu, Q. Fu, K. W. Leung, Z. C. F. Wong, R. C. Y. Choi, and K. W. K. Tsim, "The establishment of a sensitive method in determining different neurotransmitters simultaneously in rat brains by using liquid chromatography-electrospray tandem mass spectrometry," Journal of Chromatography B, vol. 879, no. 11-12, pp. 737-742, 2011.

[10] J. H. Lee, Y. J. Lee, J. K. Shin et al., "Effects of triterpenoids from Poria cocos Wolf on the serotonin type $3 \mathrm{~A}$ receptor-mediated ion current in Xenopus oocytes," European Journal of Pharmacology, vol. 615, no. 1-3, pp. 27-32, 2009.

[11] J. Winer, C. K. S. Jung, I. Shackel, and P. M. Williams, "Development and validation of real-time quantitative reverse transcriptase-polymerase chain reaction for monitoring gene expression in cardiac myocytes in vitro," Analytical Biochemistry, vol. 270, no. 1, pp. 41-49, 1999.

[12] J. W. Commissiong, "Monoamine metabolites: their relationship and lack of relationship to monoaminergic neuronal activity," Biochemical Pharmacology, vol. 34, no. 8, pp. 1127-1131, 1985.

[13] R. K. W. Schwarting and J. P. Huston, "Behavioral concomitants of regional changes in the brain's biogenic amines after apomorphine and amphetamine," Pharmacology Biochemistry and Behavior, vol. 41, no. 4, pp. 675-682, 1992.
[14] T. H. H. Pang, F. C. F. Ip, and N. Y. Ip, "Recent development in the search for effective antidepressants using traditional Chinese medicine," Central Nervous System Agents in Medicinal Chemistry, vol. 8, no. 1, pp. 64-71, 2008.

[15] H. Dang, Y. Chen, X. Liu et al., "Antidepressant effects of ginseng total saponins in the forced swimming test and chronic mild stress models of depression," Progress in NeuroPsychopharmacology and Biological Psychiatry, vol. 33, no. 8, pp. 1417-1424, 2009.

[16] H. Dang, L. Sun, X. Liu et al., "Preventive action of Kai Xin San aqueous extract on depressive-like symptoms and cognition deficit induced by chronic mild stress," Experimental Biology and Medicine, vol. 234, no. 7, pp. 785-793, 2009.

[17] L. Liu, Y. Luo, R. Zhang, and J. Guo, "Effects of ginsenosides on hypothalamic-pituitary-adrenal function and brain-derived neurotrophic factor in rats exposed to chronic unpredictable mild stress," Zhongguo Zhongyao Zazhi, vol. 36, no. 10, pp. 1342-1347, 2011.

[18] Y. Hu, H. B. Liao, G. Dai-Hong, P. Liu, Y. Y. Wang, and K. Rahman, "Antidepressant-like effects of 3,6'-disinapoyl sucrose on hippocampal neuronal plasticity and neurotrophic signal pathway in chronically mild stressed rats," Neurochemistry International, vol. 56, no. 3, pp. 461-465, 2010.

[19] P. Liu, D. X. Wang, D. H. Guo et al., "Antidepressant effect of 3', 6-disinapoyl sucrose from Polygala tenuifolia willd in pharmacological depression model," Chinese Pharmaceutical Journal, vol. 43, no. 18, pp. 1391-1394, 2008.

[20] M. Li and H. Chen, "Antidepressant effect of water decoction of Rhizoma acori tatarinowii in the behavioural despair animal models of depression," Journal of Chinese Medicinal Materials, vol. 24, no. 1, pp. 40-41, 2001.

[21] Y. H. Park, I. H. Son, B. Kim, Y. S. Lyu, H. I. Moon, and H. W. Kang, "Poria cocos water extract (PCW) protects PC12 neuronal cells from beta-amyloid-induced cell death through antioxidant and antiapoptotic functions," Pharmazie, vol. 64, no. 11, pp. 760-764, 2009.

[22] J. J. Schildkraut, "The catecholamine hypothesis of affective disorders: a review of supporting evidence," The American journal of psychiatry, vol. 122, no. 5, pp. 509-522, 1965.

[23] E. Castrén, V. Võikar, and T. Rantamäki, "Role of neurotrophic factors in depression," Current Opinion in Pharmacology, vol. 7, no. 1, pp. 18-21, 2007.

[24] F. Karege, G. Perret, G. Bondolfi, M. Schwald, G. Bertschy, and J. M. Aubry, "Decreased serum brain-derived neurotrophic factor levels in major depressed patients," Psychiatry Research, vol. 109, no. 2, pp. 143-148, 2002.

[25] C. Aydemir, E. S. Yalcin, S. Aksaray et al., "Brain-derived neurotrophic factor (BDNF) changes in the serum of depressed women," Progress in Neuro-Psychopharmacology and Biological Psychiatry, vol. 30, no. 7, pp. 1256-1260, 2006.

[26] J. A. Siuciak, D. R. Lewis, S. J. Wiegand, and R. M. Lindsay, "Antidepressant-like effect of brain-derived neurotrophic factor (BDNF)," Pharmacology Biochemistry and Behavior, vol. 56, no. 1, pp. 131-137, 1996.

[27] D. H. Overstreet, K. Fredericks, D. Knapp, G. Breese, and J. McMichael, "Nerve growth factor (NGF) has novel antidepressant-like properties in rats," Pharmacology Biochemistry and Behavior, vol. 94, no. 4, pp. 553-560, 2010.

[28] Y. Kim, S. H. Kim, Y. S. Kim, Y. H. Lee, K. Ha, and S. Y. Shin, "Imipramine activates glial cell line-derived neurotrophic factor via early growth response gene 1 in astrocytes," Progress in Neuro-Psychopharmacology and Biological Psychiatry, vol. 35, no. 4, pp. 1026-1032, 2011. 
[29] N. Nishiyama, Y. Zhou, and H. Saito, "Beneficial effects of DX9386, a traditional Chinese prescription, on memory disorder produced by lesioning the amygdala in mice," Biological and Pharmaceutical Bulletin, vol. 17, no. 12, pp. 1679-1681, 1994.

[30] L. H. Mu, Z. X. Huang, P. Liu, Y. Hu, and Y. Gao, "Acute and subchronic oral toxicity assessment of the herbal formula KaiXin-San," Journal of Ethnopharmacology, vol. 138, no. 2, pp. 351-357, 2011. 


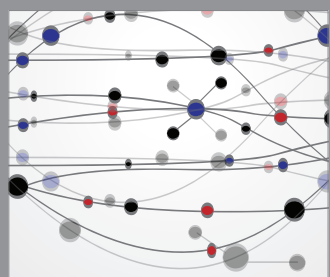

The Scientific World Journal
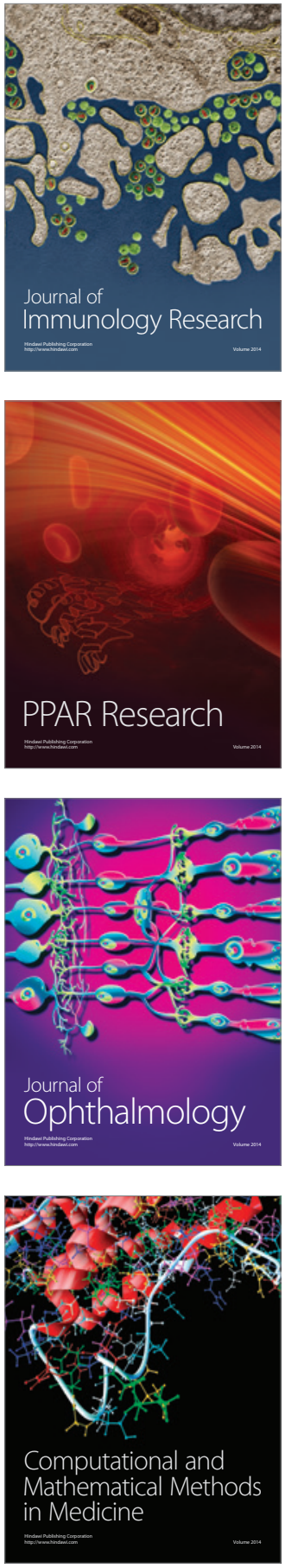

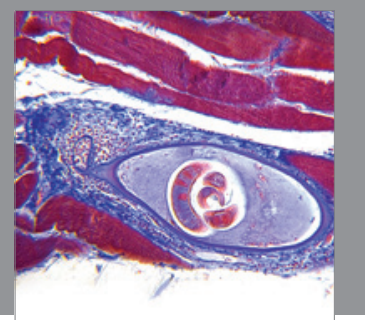

Gastroenterology

Research and Practice
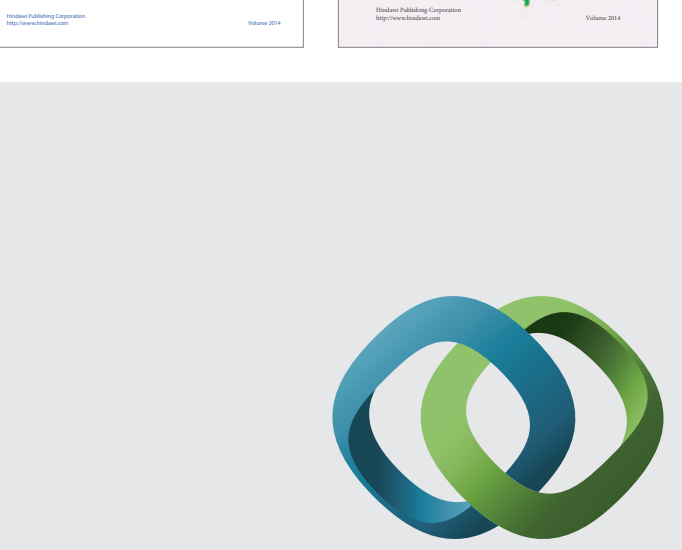

\section{Hindawi}

Submit your manuscripts at

http://www.hindawi.com
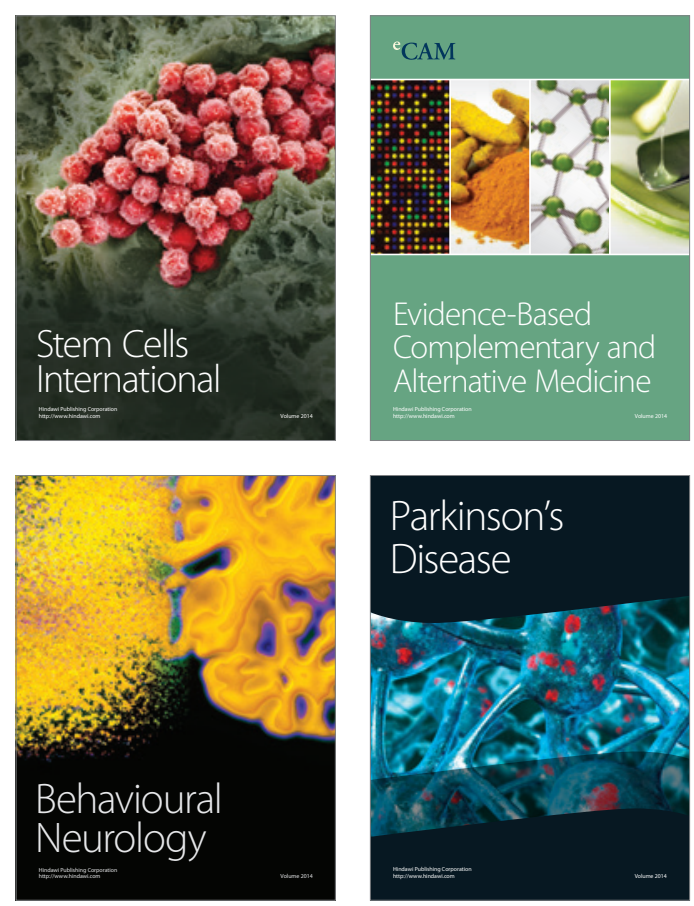

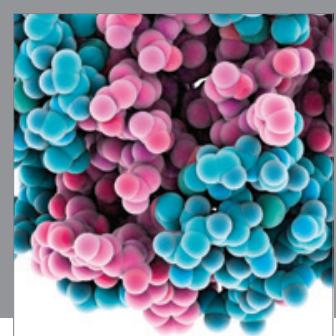

Journal of
Diabetes Research

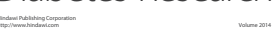

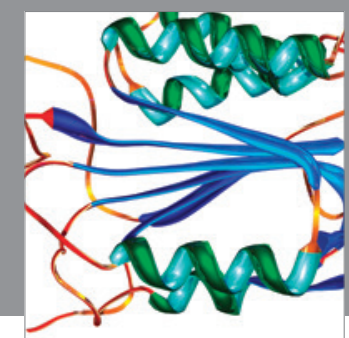

Disease Markers
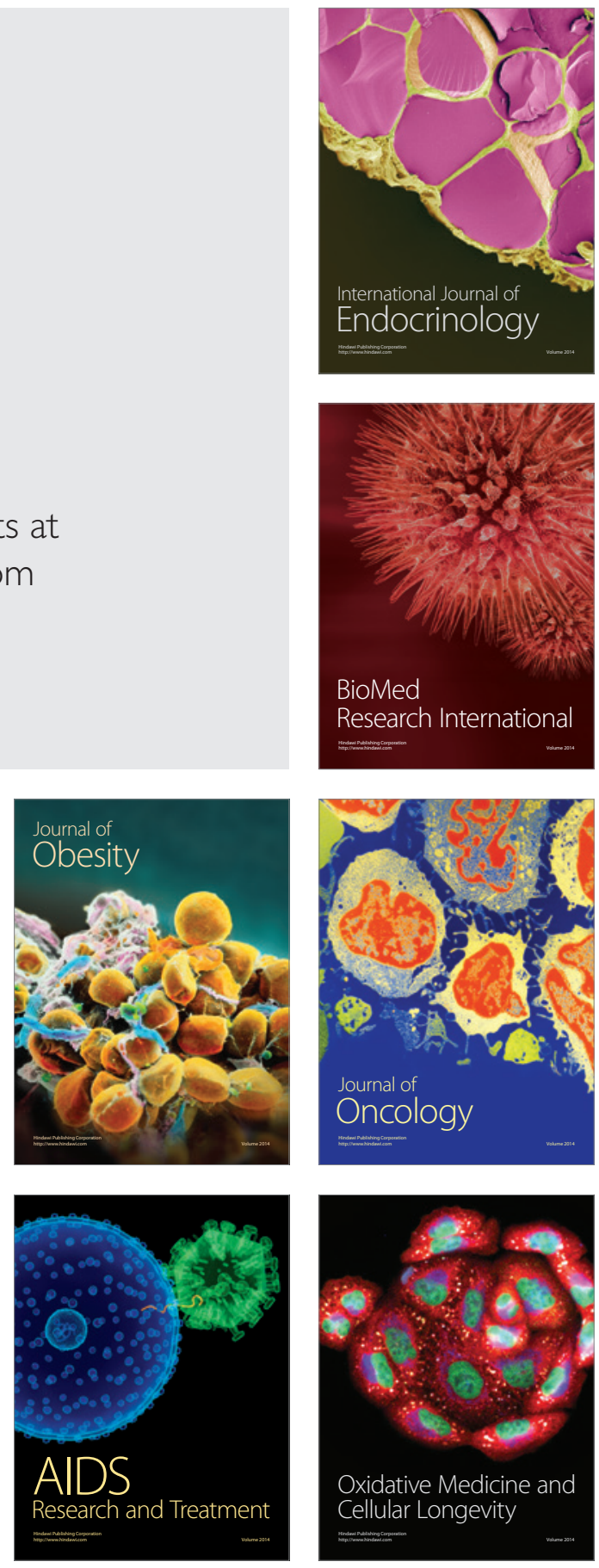